\title{
The big world of tiny things for little people
}

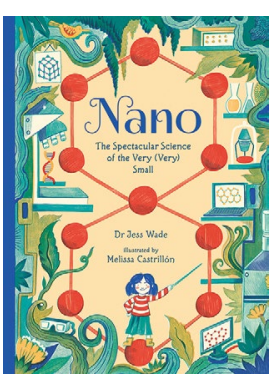

\author{
Nano: The \\ Spectacular \\ Science of the \\ Very (Very) Small
}

By Jess Wade; illustrated by Melissa Castrillón

WALKER BOOKS: 2021. 32 PP. $E 12.99$

t's been a while since I visited an actual bookstore and discovered an unexpected read. Sometime before the COVID-19 restrictions deprived me of this joy, I remember browsing picture books in search of a present for a friend's daughter. There was an abundance of books introducing children to science and the natural world: the Solar System, volcanoes, wonders of the ocean, evolution for kids. I looked at all of those, but the lack of physics subjects beyond astronomy was glaring. Next time I head to a bookstore, at least some of that shelf space will be occupied by Jess Wade's first book, Nano: The Spectacular Science of the Very (Very) Small, in which she shares her love for materials science with future generations.

The first thing that struck me when I picked up Nano were Melissa Castrillón's beautiful illustrations, which frame the cover of the book as well as the story inside. With their bold colours, broad strokes and floral patterns, they reminded me of South American fabrics, and I felt instantly transported to the visual world they create - an enchanted forest for science. Wade too was drawn to Castrillón's nature-inspired style and the power of her illustrations. And together they tell the story of nanomaterials through the intricate interplay of words and images, as any good picture book should.

Nano begins in the bedroom of a little girl who takes us on a journey by naming all the materials surrounding her - and then diving right into those materials to the atoms they comprise. Indeed, the book dedicates a full double page to the idea of atoms as the building blocks of everything. Thus the scene is set for the little girl to take the reader from familiar objects and materials such as chalk, to human-made nanomaterials such as graphene, which must seem exotic to most children. From there, she takes us straight to a laboratory where scientists make and study them, before exploring the current and future applications of graphene.

The narrative that Wade and Castrillón weave around the little girl is that of a fascination with the world around us - a world that is entirely made from materials, from atoms. Children and scientists share this curiosity to understand how nature works, and it makes for an excellent way of introducing young people to both the findings and the methods of science.

Wade didn't want to write the kind of '50 amazing facts' books that she grew up with, but thought it important to introduce her young readers - and their parents - to the process of making discoveries. "When you're taught science at school, you're just learning what other people have done, or following instructions a teacher has told you to do," Wade says. Of course, that's not an option for a scientist intent on finding something new.

For me, this additional focus on how we do science is what makes Nano stand out from many books for young people, in which science is often presented as either a collection of hard and fast facts or as the work of a handful of exceptional people. Although these can equally fuel a child's fascination for the natural world, they can make the pursuit of science feel alien or like a thing of the past. Wade thinks that "as a young person you have a misconception that scientists are somehow separated from reality, working in isolation in old and dusty laboratories and not interacting with the world around them."

Such misconceptions aren't surprising, because most children don't grow up around scientists, and these are the people Wade really wants to reach with her book. "I'd like lots of people, lots of young people, who have no access to science, to read it. Young people who don't have scientists as parents, who don't go to science museums on the weekend, or don't watch David Attenborough on a Sunday night. I'd like them to read it and to see that honestly everyone can become a scientist, and see scientists using science to solve some really big challenges about the world."

This message that science is for everyone runs through the entire book. The scientists in the lab and the other kids the girl meets throughout the book are from different backgrounds, but this diversity isn't explicitly mentioned, which I found a powerful choice. Wade and Castrillón paint a picture of a world where the doors to the lab are open to everyone, and their young readers can imagine themselves stepping through those doors one day.

Halfway through the book, it occurred to me that the little girl who led me through the narrative doesn't have a name. Although Wade assures me this wasn't a conscious decision on her part, I believe it invites the reader to step into the girl's shoes and explore the wonderful world of nanomaterials. This too is a subtle way to reinforce the message that everyone can explore the world and become a scientist, and the book ends on just this statement: the young reader may be the one holding the key to future discovery.

Although I would never forgo the joy of browsing a bookshop for alternatives, Wade and Castrillón's beautiful and engaging picture book is certain to be one of my future presents for the primary school-age children in my life.

\section{Reviewed by Nina Meinzer $\bowtie$ \\ Senior Editor, Nature Physics.

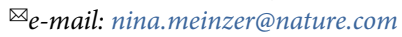

Published online: 9 June 2021

https://doi.org/10.1038/s41567-021-01264-6 